\title{
EXPECTATIONS, EXPERIENCES AND \\ RESULTANT OUTCOMES \\ DURING THE SOCIALISATION \\ OF NEWCOMERS IN SMALL \\ MANUFACTURING FIRMS: A \\ SOCIALISATION AGENT \\ PERSPECTIVE
}

\author{
Robbie Field \\ School of Business \\ Eastern Institute of Technology
}

Dr Alan Coetzer

School of Management

Faculty of Business and Law

Edith Cowan University

\begin{abstract}
The extent to which pre-employment (pre-encounter) and post-employment (encounter) expectations and experiences of both newcomers and organisational insiders (socialisation agents) are met during the socialisation of newcomers are critical in determining newcomer adjustment, establishing person-organisation (P-O) and person-job (P-J) fit, and in achieving organisational socialisation $(O S)$ outcomes such as performance, job satisfaction and intention to stay/quit. The purpose of this paper is to examine pre-encounter and encounter expectations and experiences of newcomers and socialisation agents and resultant outcomes during the socialisation of newcomers in small manufacturing firms, from the perspectives of socialisation agents. Data were collected regarding the socialisation of newcomers through semistructured interviews (incorporating critical incidents) with socialisation agents. Findings of this exploratory qualitative study indicate that expectations are created for both newcomers and socialisation agents during preencounter socialisation processes such as recruitment and selection, as well as through information obtained from other sources. The extent to which experiences match these expectations during the OS process, affect aspects such as newcomer adjustment, $P$-O fit and key outcomes that include task performance and turnover. The implications of these findings for practice are highlighted and the paper concludes with suggestions for further research.
\end{abstract}

\section{Introduction}

New employment represents challenges for both the new employee and the organisation. The newcomer faces novel work and organisational situations that requires new knowledge and skills to adjust to these unfamiliar circumstances, whilst for the organisation the uncertainty newcomers experience increases the likelihood of labour mobility that impacts on retention (Filstad 2004). This process of newcomer adjustment to their new work and organisational context, through learning the required knowledge, skills and attitudes to function as fully effective and integrated members of the organisation, is referred to as organisational socialisation (OS) (e.g. Fisher 1986; Van Maanen 1978).

Most newcomer socialisation takes place during the early period before organisational entry (pre-encounter phase) and soon after organisational entry (encounter phase) of the OS process, with these phases being critical in determining newcomer adjustment and achieving successful OS outcomes (Cooper-Thomas, Van Vianen and Anderson 2004; Kammeyer-Mueller and Wanberg 2003; Kickul 2001), such as employee performance and an organisation's ability to retain staff (i.e. turnover) (Cooper-Thomas and Anderson 2002; Mitchell, Holtom, Lee, Sablynski and Erez 2001; Slattery, Selvarajan and 
Anderson 2002). Pre-encounter expectations refer to expectations created prior to organisational entry, while encounter experiences describe perceptions of experiences after newcomers' commence employment (Sutton and Griffin 2004). Pre-entry expectations are assessed against the reality of experiences that commence from the time of the initial period of entry into the new working environment (De Vos, Buyens and Schalk 2003). Notwithstanding the importance of the pre-encounter and encounter phases of socialisation for newcomer learning and adjustment and resultant outcomes being recognised in the literature (Cooper-Thomas et al 2004; KammeyerMueller and Wanberg 2003; Kickul 2001); little OS research has been conducted on establishing the relationship between pre-encounter and encounter expectations and experiences (Carr, Pearson, Vest and Boyer 2006; Fisher 1986).

The critical role of various organisational insiders (e.g. supervisors and co-workers) who take on the role of 'socialisation agents' during the pre-encounter and encounter phases of the OS process, in assisting with newcomer learning and adjustment is widely recognised (Beery 2000; Cooper-Thomas and Anderson 2006). Socialisation agents contribute towards newcomer adjustment to their new work environments by providing support, information and work relevant resources (Morrison 2002). When newcomers commence work, socialisation agents compare their pre-encounter expectations of newcomer adjustment to their actual experiences of newcomer behaviour in their new work environment (Garavan and Morley 1997). However, little is known about the roles and perceptions of these "insiders" during the OS process (Morrison 2002).

The small body of research into the HRM practice of OS has been conducted in primarily large organisations (e.g. Ashforth et al 2007; Cable and Parsons 2001; CooperThomas and Anderson 2002; Hart, Miller and Johnson 2003). Small firms (however defined) represent the majority of businesses in most countries and, as is the case in New Zealand, make a major contribution towards business activity, economic development and employment generation (Battisti and Perry 2008; Massey 2005). In rural regions in particular (such as the context for the current study), the small firm sector is regarded as a significant source of employment and economic growth (Alonso 2009; Vaz, Cesario and Fernandes 2006). The capacity of the small firm sector to make contributions to employment and economic growth is contingent upon the ability of these firms to attract and retain high performing employees (Deshpande and Golhar 1994; Wiesner and McDonald 2001). Despite the importance of small firms to the economy and employment and the role of socialisation in achieving outcomes such as increasing staff performance and reducing turnover, there is an acute shortage of research in small firms and many questions remain unanswered as to how small firms socialise newcomers and ensure they make effective adjustments to their new work environment (Cardon and Stevens, 2004).

\section{Aim of the Study}

The primary aim of this study was to examine socialisation agents' pre-employment expectations of newcomers' ability to learn and adjust to their new environment in relation to socialisation agents' actual experiences of newcomers' work-related behaviours, and resultant outcomes in small firms.

The specific research objectives were:

1. To investigate socialisation agents' expectations of newcomers' ability to learn and adjust to their new work environment and their actual experiences of newcomers' work related behaviours.

2. To examine the potential effects of the extent to which socialisation agents' expectations and actual experiences of newcomers' ability to learn and adjust to their new work environment influence key individual and organisational outcomes.

For the purposes of this study a firm is defined as small if it employs 10 to 49 full-time equivalent (FTE) staff. In New Zealand, the threshold of 49 employees is often used by researchers to define the small firm when they study HRM (e.g. Cameron and Massey 1999; Cameron et al 2006; Gilbert and Jones 2000; Lewis, Massey, Ashby, Coetzer and Harris 2007; Massey 2005). Using this definition, small firms in Hawke's Bay make up in excess of $95 \%$ of businesses in the region. They play a vital role in creating employment and are regarded as the backbone of regional economic growth. The manufacturing sector is the largest contributor to gross domestic product in the region over the past six plus years, has also been the largest employer in the small firm sector and supports the important horticulture and viticulture sectors in Hawke's Bay (Ministry of Economic Development (MED) 2008; Statistics New Zealand 2008).

\section{Literature Review}

\section{Nature of Organisational Socialisation}

Defining OS has progressed from a general description of "learning the ropes" (Schein 1968; Van Maanen 1978), to being defined as a learning process through which newcomers make the transition from organisational 'outsider' to effective participating and contributing 'insider', while adjusting to their roles in the context of their new workplace environment (Bauer et al 2007; Cooper-Thomas and Anderson 2006; Feldman 1976; Feldman 1981). Although definitions of OS have developed over time, current conceptualisations and research (e.g. Cooper-Thomas and Anderson 2006; Saks and Ashforth 1997; Saks, Uggerslev and Fassina 2006) continues to focus on the two key 'traditional' aspects of OS, namely: (1) that it is a learning process; and (2) it concerns newcomer adjustment to their environments (e.g. Feldman 1976; Jones 1983; Jones 1986; Louis 1980; Van Maanen and Schein 1979). OS is ubiquitous, 
occurring each and every time an employee crosses an external boundary (e.g. between two organisations) or an internal boundary (e.g. a departmental transfer within an organisation) (Van Maanen and Schein 1979). Whenever this occurs, functionally, the individual is considered a 'newcomer', with ongoing learning crucial to successful adjustment of the new employee to the work environment (Van Maanen 1978).

\section{Pre-encounter and Encounter Expectations and Experiences}

Two key phases of the OS process that occur before and after the crossing of organisational boundaries are the pre-encounter and encounter phases respectively. The pre-encounter or anticipatory phase is the first stage of the OS process that occurs before the newcomer enters the organisation (Ardts, Jansen and Van Der Velde 2001; Feldman 1976). The next stage of the OS process is the encounter or accommodation phase that commences when the newcomer enters the organisation (Allen 2006; Ardts et al 2001; Bauer et al 1998; Van Maanen 1978). During the critical transition period prior to and just after crossing an organisational boundary, such as the outsiderto-insider passage that occurs during the pre-encounter and encounter phases of socialisation, adjustment is at its most intense and problematic (Van Maanen and Schein, 1979). This is because the gap between expectations formed prior to entry and perceptions of reality experienced soon after joining the organisation is probably at its widest during this period (Fisher 1986; Nicholson and Arnold 1991). At the same time, the early period before (pre-encounter) and following organisational entry (encounter) are when most socialisation takes place and are critical in determining newcomer adjustment, establishing the long lasting relationship between employee and employer and in achieving successful OS outcomes (Ashford and Black 1996; Buckley, Fedor, Veres, Wiese and Carraher 1998; Cooper-Thomas et al 2004; Filstad 2004; KammeyerMueller and Wanberg 2003; Kickul 2001).

The degree to which prior expectations, established before entering the organisation (pre-encounter phase), match experiences and are met on entering the organisation (encounter phase), determines the success of newcomer adjustment and adaptation to their new work environment (Starr and Fondas 1992). Met expectations are defined by Porter and Steers (1973) as "the discrepancy between what a person encounters on the job in the way of positive and negative experiences and what he expected to encounter" (p.152). Empirical research confirms that met expectations are strongly related to job satisfaction, organisational commitment, intention to quit and job survival (Saks 1994; Wanous, Poland, Premack and Davis 1992). On the other hand, unmet expectations are an inevitable result of the experience of entering an unfamiliar organisational environment, when differences between expectations and experiences are apparent (Louis 1980). This leads to outcomes such as lower levels of organisational commitment and higher levels of intention to quit (Saks 1994; Saks and Ashforth 2000).
During the pre-encounter expectations and encounter experiences phases of the OS process newcomer learning and adjustment to the culture of the organisation, fellow employees, and the demands of the job occur (Chao 1991; Van Maanen and Schein 1979). The significance of socialisation in determining 'fit' between the newcomer and the new work environment is supported by research (Chao et al 1994; Chatman 1991). The degree of compatibility ('fit') between pre-encounter expectations and encounter experiences between newcomers and their new work environment in relation to certain characteristics is defined as person-environment (P-E) fit (Kristof-Brown, Zimmerman and Johnson 2005; Saks et al 2006). Three types of P-E fit have been identified in the socialisation literature. These are the extent of compatibility between: (1) the individual and culture, values and norms of the organisation (P-O fit); (2) the individual and their work group (P-G fit); and (3) the abilities of the individual and the task requirements of the job (P-J fit) (Cable and Parsons 2001; Chatman 1991; Kristof-Brown et al 2005; Saks and Ashforth 1997; Saks, et al 2006). Although the various types of P-E fit are interrelated, empirical evidence provides support for the distinction between P-O fit, P-G fit and P-J fit (Kristof 1996).

Despite the importance of expectations that influence newcomer adjustment prior to organisational entry (preencounter), research over the last 20 plus years has paid little attention to and does not clarify the role of pre-entry variables in newcomer adjustment (Jones 1983; Kammeyer-Mueller and Wanberg 2003). Most organisational socialisation theorists and researchers agree that the encounter phase of OS is a key moment for the newcomer (Barge and Schlueter 2004; KammeyerMueller and Wanberg 2003). Because of the unfamiliarity and uncertainty that exists when newcomers are exposed to their new environments, the early experiences when newcomers enter the organisation plays a particularly important role in the adjustment of the newcomer to the organisation (De Vos, Buyens and Schalk 2003). During the encounter phase of socialisation, those involved with the 'onboarding' of newcomers (i.e. socialisation agents) have certain expectations as to how newcomers will adjust to their new work and job environment. They then compare their actual experiences of newcomer adjustment to their expectations. The more rigorous and intensive the socialisation practices are pre-entry and post-entry; the more congruent are the newcomer attitudes and behaviours with those of the organisation (Chatman 1991). According to Reichers (1987), the encounter phase ends when newcomer anxiety is reduced and the meanings newcomers and insiders attach to organisational life is similar.

\section{Organisational Socialisation Outcomes}

An OS outcome variable is a criterion by which progress through the OS process is measured and judged (Feldman 1981). For example, job satisfaction, organisational commitment, performance and intention to quit are consistently viewed by researchers as either adjustment outcomes or indicators of OS success (e.g. Cooper- 
Thomas and Anderson 2002; Cooper-Thomas and Anderson 2006; Mitchell, Holtom, Lee, Sablynski and Erez 2001; Saks and Ashforth 1997; Slattery, Selvarajan on newcomer and Anderson 2002). Key OS outcomes are dependent learning and adjustment to the 'job' (e.g. task mastery (ability to perform the job)), social integration (fitting in with work group) (Kammeyer-Mueller and Wanberg 2003; Saks and Ashforth 1997; Wanberg and Kammeyer-Mueller 2000) and intention to quit (Bauer et al 2007; Saks et al 2007).

As previously noted, turnover is probably the most important OS outcome for the organisation (CooperThomas and Anderson 2006), and the relationship between OS and turnover (i.e. retention) is highlighted in various OS studies (e.g. Allen 2006; Ashforth et al 2007; Bauer et al 2007; Buckley et al 1998; Carr et al 2006; Cooper-Thomas and Anderson 2006; De Vos et al 2003; Feldman 1981).

\section{Role of Socialisation Agents in Organisational Socialisation}

Although newcomers play an active role in their own socialisation and sense making by seeking information and feedback (Cooper-Thomas and Anderson 2002; Feldman 1981; Morrison 1993), a large part of newcomer knowledge about the organisation and the job is determined by the amount and accuracy of information obtained from the employing organisation's sources (Carr et al 2006). The important role of insiders, such as supervisors and co-workers, as socialisation agents (Starr and Fondas 1992) in newcomer adjustment is confirmed in empirical research and highlighted in the socialisation literature (e.g. Allen 2006; Cooper-Thomas and Anderson 2006; Morrison 1993; Morrison 2002; Louis, Posner and Powell 1983; Ostroff and Kozlowski 1992).

Socialisation agents are those employees inside an organisation who influence the attitudes and behaviours of newcomers (Feldman 1994). Supervisors and colleagues, as key socialisation agents, are 'insiders' who support newcomer adjustment and help them to "learn the ropes" (Morrison 1993; Morrison 2002). These socialisation agents are the most important sources of socialisation information and have the most influence on newcomer adjustment (Beery 2000). They are also viewed by newcomers as more useful sources of information than formal OS programmes in assisting with newcomer adjustment and achieving positive OS outcomes (Louis et al 1983; Cooper-Thomas and Anderson 2006). More specifically, interactions between newcomers and socialisation agents during the early encounter stage of the socialisation process are recognised as the primary vehicle through which socialisation occurs (Reichers 1987). It is, thus, also important to examine the role of socialisation agents in the socialisation process (Allen 2006).

\section{Method}

This exploratory, qualitative study used the Critical Incident Technique (CIT) to gather data through in-depth, semi-structured, face-to-face interviews. The CIT is particularly useful for investigating, interpreting and understanding significant (critical) work incidents from the perspective of those involved in work processes (such as socialisation agents), and obtaining rich and complete accounts of the situation studied (Atkinson 2007; Greenwell, Lee and Naeger 2007; Lambrecht, Redmann and Stitt-Gohdes 2004). Critical incidents are events, experiences, activities, or behaviours that are significant to those involved in a process, and which positively or negatively affect the outcomes of a process (Schluter, Seaton and Chaboyer 2007).

A database of small manufacturing firms located in the Hawke's Bay region was used to recruit the 17 socialisation agents who participated in this study. The sample size for this study was determined by the number of incidents, rather than by the number of participants (Flanagan 1954), with each critical incident being a selfcontained unit of analysis (Patton 2002). A series of preprepared questions and associated probes related to the research objectives were prepared for the purpose of gathering the recommended minimum of 50 critical incidents to ensure a sufficient quantity, and the necessary quality of usable data (Flanagan 1954; Schluter et al 2007). The entire interview process was piloted before implementation and the same procedures were followed for all interviews when the actual study commenced. Interviews were digitally recorded in order to enhance reliability of the content analysis (i.e. code-recode reliability and inter-coder reliability) and to ensure the data were accurately transcribed and the interview information retained (Silverman 2000). The interviews were digitally recorded and transcribed verbatim to facilitate data analysis (Raub, Alvarez and Khanna 2006). Copies of interview transcripts were forwarded to participants for review, and to assist in verifying the accuracy of the transcription process.

As part of the initial data analysis the researcher read and reread the transcripts for accuracy and completeness of information. This process enhances reliability through the identification of consistencies and inconsistencies (Miles and Huberman 1994; Schluter et al 2007). During this process, reflective comments were recorded on the interview transcripts (Miles and Huberman 1994; Patton 2002). This was followed by the process of content analysis, which involved the coding and categorisation of data and the subsequent identification of themes within the categories (Babbie 2004; Patton 2002). A colour code was assigned to two broad categories developed from the study aim and research objectives. These two categories are: (1) pre-encounter and encounter expectations and experiences; and (2) outcomes of pre-encounter and encounter expectations and experiences. Interview transcripts were then colour coded and the colour coded 
data strips were cut and pasted into the appropriate category.

To facilitate the identification of themes within each of the categories a matrix was developed (e.g. Lambrecht et al 2004; Stitt-Gohdes, Lambrecht and Redmann 2000). Rows in the matrix indicated interview participants (17) and columns represented the categories. Data strips identified as critical incidents from the interview transcripts were entered as direct quotes into the columns of the matrix representing the categories. The data were reviewed to identify recurring themes (Patton 2002). The themes that emerged within each of the two categories are identified and elaborated on below.

\section{Findings}

The major themes identified within the pre-encounter expectation and encounter experiences and outcomes categories are illustrated through quotations taken from interview transcripts. To maintain confidentiality, actual names of participants in the study and organisations are not identified. Where names are mentioned in quotations, pseudonyms are used.

\section{Category 1: Pre-encounter Expectations and Encounter Experiences}

Two major themes emerged from analysis of the data in the pre-encounter expectations and encounter experiences category. These were: (1) various selection methods create expectations of newcomer learning and adjustment that are met/unmet; and (2) compatibility between the newcomer and the work environment is assessed in relation to: person-organisation fit; person-group fit; and person-job fit.

Socialisation agents' accounts of incidents included references to the various selection methods that were used and how these methods had shaped their pre-employment expectations of newcomers' ability to learn and adjust to their new work. These methods included curriculum vitae (CVs), interviews and work samples. CVs were widely used with varying degrees of success for yielding information about newcomers that create expectations of their ability to learn and adjust to their new work environment that are sometimes unmet and in other instances met when employment commences. The following interview excerpt illustrates how expectations based on information contained in a $\mathrm{CV}$ were not matched by actual experiences of a newcomer's ability to perform the requirements of the job:

If they've presented a CV saying they can do this and do that I expect people to do it straight away. They've got that stuff on their CV I expect them to do that. We actually had one guy that started and I actually got to see his CV and looked at that and thought "you're the man". He looked brilliant. He actually looked better than the dude I just finished talking about from Hamilton. Looking good on paper and actually being able to do the practical side of things, there was a big void, a real big void. He's welding tickets, he could use this machine, and he could use that machine. He'd done this job, he'd done that job, but actually when it came to practice he wasn't actually that good. Some of our stainless steel I had to actually go back and cut them all up and do it again.

In contrast, sometimes socialisation agents' expectations, which are shaped by information included in a newcomer's CV, are not only met, but exceeded:

There's one individual we employed in June of last year, and he had a very good $\mathrm{CV}$, but very quiet soft spoken guy. Doesn't say much, but when I looked at his CV, I grabbed him straight away. On paper he looked really good. He was a guy who had actually been out of the trade for a couple of years. He'd done an apprenticeship, he'd done trade certificate plus advance trade and his paperwork said he was also an apprentice of the year, which is what I picked up on. There was one activity where he was asked to machine a tail drum for a client and he did it in about half the amount of time as what the other tradesmen in the machine shop have. He'd been here for about two months. But another incident I know about on site when he was very new to the company and the feedback got from a client was that he brought it back within a day.

In the small firms studied, it was not uncommon to find interviews being used in conjunction with other selection methods. The information about the applicant generated from these multi-methods also helped to shape preemployment expectations of newcomers' ability to learn and adjust to their new work environment. The interview excerpt below illustrates how an interview and a work sample were used to predict newcomer learning and adjustment:

At the time we were looking for a worker in our manufacturing area which involved matching skins, trimming skins and the final finishing and grading of the skins and he came across very good at the interview. We gave him a couple of skins to trim just to monitor the dexterity because the trimming can be quite hard to pick up at the initial stage and he managed that well and in the interview stage we discussed his previous employment at "The Daily Dispatch" and what he did there and it involved similar quality checks and a bit of work with colour inks and colour matching, which we thought carried some similarities with matching up the skins, looking at the colour skins to match multiples together. So it was the quality side of his work there that we picked up would have definite use for. And the colour aspect because they are matching skins together and that's where we need them to be the same colours to match up and so that along with that trial with his trimming, we thought OK, he's got the physical 
ability plus a definite eye for quality as well, so piecing the two together we thought, we've got a good man here. His workmanship, quality-wise, he's supervisors been very happy with his quality right from the word go. It goes back to how quickly he picked up the trimming, matching of skins which he's done up to a very high standard and a very high quality, and just general workmanship.

According to socialisation agents, their pre-encounter expectations and encounter experiences are used to predict the degree of compatibility ('fit') between newcomers and the work environment. More specifically, they use their pre-encounter expectations and encounter experiences to predict person-organisation fit; persongroup fit; and person-job fit. Respondents highlighted the problems that are sometimes experienced with P-O fit when newcomers move from an organisation with a strong organisational culture to an organisation with a significantly different culture and expectations are not met:

With Tom, I mean he's actually a nice guy, but I think he's still adjusting from the army to civilian life because he's not so much get in there and do things, he sort of stand back and waits for someone to tell him what to do. I think it's very cultural. I pretty much put it down to because it was such a change of environment from being armed forces coming up to the civil world, and that actually relates to the other chap from the armed forces as well at the moment, who's expectations are not where it should be. I have had him out on a couple of general fitting jobs like pulling shafts and things like that, which he was OK with, but I've since come to realise that the way things are done in the armed services are very different from what we do here. I had discussed all those cultural aspects prior and said this is a major change of environment from what you're used to working in. It may take a little bit of time to adjust.

Interestingly, when considered in relation to increasing diversity in the workplace, some socialisation agents also reported the impact that differences in national culture can have on $\mathrm{P}-\mathrm{O}$ fit:

We had a young guy, he was an Asian boy. He worked really well, we offered him employment, but during the training time he could have been injured a few times. There was one incident where we had to pull him aside and what we did, we went through all the training tasks again. All the hazards in those areas, and we got him to take us around that department and show us all the hazards, and we asked him "what was his interpretation of what could happen to him as far as being injured?". And through that we grasped that his total interpretation was totally different to ours. And we actually had to change part of training, because of that. Because we just assumed that if people read all this and saw a sign, the floor is marked off, that people would understand. So it was a learning curve for us as well. So we changed part of our training to incorporate not only learning difficulties, but that multi-cultural aspect of interpretation. There have been a couple of incidences where, we've gone "ah thank God we did it this way". Because they're concerned about compliance and they want to make a good impression, that's their culture, they would want to please and do a good job. And they just forget about the hazard of it.

Integration with the work group (P-G fit) is a key aspect of newcomer learning and adjustment to their new environment and even though a newcomer has the ability to perform the technical aspects of the job, if they are unable to fit into the team environment this can have adverse consequences:

He was a very angry person. He was always looking at what other people were up to and he was very intimidating to some of the guys on the floor. He was probably the closest you'd get for naming a school kid bully. He was just very intimidating, he'd always watch what people here were doing. He had a lot of arguments with people and he was known to have a temper. He actually dragged a person on top of a saw bench by the scruff of the neck and was going to punch his lights out. So he was very much like that. He'd throw power tools and he'd lose the plot. $\mathrm{He}$ created an unwelcoming workplace. One person mentioned that they'd drive to work and they wouldn't see his car in his car park and they thought great, he's away today. That's what it created. God help me. I had to manage him. He was actually a very clean, tidy joiner and his work was fine. His quality was fine. But people generally didn't really want to work with him.

While the emphasis placed on general 'fit' in relation to $\mathrm{P}-\mathrm{O}$ fit and $\mathrm{P}-\mathrm{G}$ fit are regarded as important by socialisation agents in small firms, the importance of P-J fit should not be underestimated. This is particularly so in a manufacturing environment where aspects such as the technical ability to meet the requirements of the job are regarded as important. The benefits of a newcomer's ability to meet the requirements of the job are clearly illustrated by the following interview excerpt:

There was one instance where he picked up a flaw in one of the drawings and he basically saved several thousand dollars of rework. I hadn't specifically told him to set this certain process to check on his job. He did that out on his own and he picked up on that. We could have just followed along with the drawings we had, which would have been right, and picked up the mistake later. It would have cost a lot of rework, but he saw it right from the beginning. 


\section{Category 2: Outcomes of Pre-encounter Expectations and Encounter Experiences}

Socialisation agents in the small firms studied reported a number of important outcomes as a result of matches or mis-matches between their pre-encounter expectations and encounter experiences as newcomers progressed through the pre-encounter and encounter phases of the socialisation process. Of the outcomes, staff turnover and work performance were identified as outcomes of particular significance for small firms. The ability of small firms to reduce voluntary employee turnover and ensure adequate levels of performance in the environment in which these firms operated were deemed to be essential to them being competitive. The interview excerpt below is an illustration of an unsatisfactory outcome (turnover) where the socialisation agent had high expectations of a newcomer being able to contribute to the organisation that were not met and resulted in the newcomer leaving the organisation on the first day of commencing employment:

Two hours after he commenced employment he was such a mess that he left the site. He was very upset and told me he was going and he didn't want to talk about it. He was very upset and left and I said "OK that's fine, I'll give you a call later and maybe you can come in tomorrow and have a talk to me". But he had had enough. It just happened straight away so he left. So I suppose that's an extreme case, and he's never returned, he's never wanted to return. His first two hours on the job affected him so badly that he refused to come back to the work site.

In certain instances, when socialisation agents' encounter experiences do not match their pre-encounter expectations and the newcomer exits the organisation, it can be of mutual benefit to both the employer and the employee:

Once she was actually here it was like "Oh dear, we had made a bad choice". Anyway, luckily for us and for her, she found another job within a month of starting with us. In the end it was great. She didn't want to be here and it wouldn't have worked. She found something she wanted to do. If she'd been here a long time and really miserable it just would have put the rest of the team down, so it was really a good case scenario in the end that she left.

The following excerpt illustrates the positive effects on work performance where the socialisation agent's experiences of a newcomer's ability to learn and adjust to their new work environment exceeded pre-encounter expectations:

He came on board and within 4 or 5 weeks I started bringing him up to speed with purchasing and so something I didn't expect was the amount of speed he'd come up to. He's exceeded expectations in particular his ability to be able to get onto a computer and start placing purchase orders. So effectively speaking he's taken off my plate $30 \%$ of my workload, which is huge and the timing of that couldn't have been better because on the other side my workload went up $30 \%$.

\section{Discussion}

The findings of socialisation agents' perspectives of (mis)matches between pre-encounter expectations and encounter experiences and resultant outcomes in small manufacturing firms contribute to the socialisation literature in a number of ways. First, feedback from socialisation agents suggests that small firms use a range of selection methods, such as CVs, interviews and work samples that serve as mechanisms in creating preemployment expectations of newcomers' ability to learn and adjust to their new environment. These types of selection methods used to determine expectations of newcomers' ability to "fit in" are chosen by small firms for their ease of use and convenience (Gilbert and Jones 2000; Kotey and Sheridan 2001) and they meet the operational needs of small firms (Barrett and Mayson 2007). While traditional methods such as CVs can be convenient, they do not always provide as reliable and accurate information of expectations of newcomers' ability to learn and adjust to their new environment as methods such as work samples do (Robertson and Smith 2001). The use of appropriate selection practices plays a key role in the development of realistic expectations (Scholaris, Lockyer and Johnson 2003). Small firms that utilise selection practices which accurately identify newcomers who are able to "fit in" make valuable contributions toward pre-employment socialisation and reduces the amount of learning and adjustment required post-employment (Coetzer and Perry 2008).

Second, the findings of this study indicate that socialisation agents' pre-encounter expectations and encounter experiences of compatibility between newcomers and their new work environments in relation to: the culture, value and norms of the organisation (P-O fit); integration with the work group (P-G fit); and ability to fulfil the requirements of the job (P-J fit) are important to small firms. These findings are consistent with the congruence sought between expectations and experiences in determining different types of 'fit' (Kristof 1996). The process of acculturation and developing an understanding of the requirements of the organisation commences preemployment (Coetzer 2006), with expectations of fit being created even during relatively brief preemployment encounters (Kristof-Brown et al 2005). During the early stages of entry (encounter) further newcomer assimilation into the cultural values and norms of the organisation (P-O fit) continues (Cable and Parsons 2001). As organisations have moved towards more teambased approaches to work, the significance of P-G fit is becoming more important (Kristof 1996). This is particularly so in small firms where employees tend to work closer together (Marlow 2000) and are also more likely to operate as a team (Heneman, Tansky and Camp 2000). Interestingly, many socialisation agents in the 
current study placed greater emphasis on the importance of general 'fit' (P-O fit and P-G fit) than on specific 'fit' with the requirements of the job (P-J fit). These findings are in keeping with small firm research that shows that $\mathrm{P}$ $\mathrm{O}$ fit tends to outweigh the importance of P-J fit (Cardon and Stevens 2004; Heneman et al 2000; Marlow 2000). This is not to undermine the importance of P-J fit for small firms, but rather to illustrate the relative importance attached to the different types of 'fit' by certain small firms. For socialisation agents who regard P-O fit and P$\mathrm{G}$ fit as more important than P-J fit, the general consensus is that the technical aspects of the job in terms of the skills and abilities to perform the requirements of the job can be learnt, whereas the other types of fit are more difficult to take on board and learn.

Finally, newcomer progression through the pre-encounter and encounter phases of the socialisation process and the relationship between expectations and experiences during these stages of socialisation have effects on key outcomes for small firms that include turnover and performance. Of the OS outcomes, turnover is probably the most important for the organisation due to costs of recruiting, selecting, training and the time it takes for newcomers to become fully productive (Cooper-Thomas and Anderson 2006). Despite the importance of turnover for small firms, very few studies have examined the impact of employee practices, including OS, on turnover in these firms (Cardon and Stevens 2004). As far as work performance is concerned, the pre-encounter and encounter phases of OS are key contributors to getting newcomers "up to speed" in terms of their performance as quickly and effectively as possible (Van Maanen and Schein 1979). Required levels of newcomer performance are important for: the organisation as a form of "return on investment" related to the costs of onboarding the newcomer; the newcomer to ensure ongoing employment and increased well-being; and for work colleagues who expect newcomers to "pull their weight" (Cooper-Thomas and Anderson 2006). In addition, given the human, material and financial resource constraints faced by small firms when compared to larger firms, the positive effects of the speedy and effective adjustment of newcomers on the critical OS outcomes of turnover and performance are of particular significance, (McAdam 2000; McAdam 2002).

This study has illustrated the relationship between preencounter expectations and encounter experiences and resultant outcomes. Expectations formed during the preencounter phase of socialisation are weighed up against the realities experienced when newcomers commence employment, which in turn influences resultant outcomes (Garavan and Morley 1997). In summary, the ability of small firms to effectively and efficiently progress newcomers through the pre-encounter and encounter phases of the OS process are critical in facilitating newcomer learning and adjustment, establishing the long lasting relationship between employee and employer and in achieving positive OS outcomes, such as reducing turnover and increasing performance (Cooper-Thomas, et al 2004; Filstad 2004; Kammeyer-Mueller and Wanberg 2003).

\section{Implications for Practice}

The findings of this study have three key implications for practice. First, small firms should strive to find ways to ensure that pre-encounter expectations and encounter experiences of newcomer learning and adjustment are met. Incongruence between pre-encounter expectations and encounter experiences result in unmet expectations (Scholaris et al 2003). The selection of competent socialisation agents who have a clear understanding of their roles and responsibilities, which include involvement in pre-encounter practices such as selection and encounter practices such as induction, can assist in the speedy and effective progress of newcomers through the pre-encounter and encounter phases of the socialisation process. This would contribute towards ensuring that pre-encounter expectations of newcomers' ability to learn and adjust to their new work environment best match experiences when newcomers enter the new work environment.

Second, small firms should consider the nature and significance of the different types of 'fit' for their organisation. As previously noted, many small firms view general fit in relation to $\mathrm{P}-\mathrm{O}$ fit and $\mathrm{P}-\mathrm{G}$ fit as more important than P-J fit. In reality, the significance of all the different types of P-E fit are of importance to small firms in ensuring that expectations and experiences of newcomers learning and adjustment to their new work environment result in achieving the desired outcomes. The resource constraints faced by small firms (Stevens 2007), together with the risks and costs associated with the unsuccessful onboarding of newcomers (Kotey and Slade 2005), means that small firms do not have the luxury of a 'misfit' between the newcomer and the new work environment. The use of a three month trial period by small firms is a way to determine newcomer fit and appears to be on the increase since the New Zealand government introduced new labour legislation with effect from 1 March 2009. In accordance with this legislation employers who employ 19 or fewer employees will be able to employ new employees on a trial period of up to 90 calendar days (Department of Labour (DOL) 2009). A three month trial period can be viewed as a type of "job tryout" that provides both the newcomer and the organisation with the opportunity to determine the degree of compatibility between the newcomer and the organisation, and to assess the ability of the newcomer to learn and adjust to their new environment.

Finally, as previously noted, the pre-encounter and encounter phases are when most socialisation takes place and are critical in determining newcomer learning and adjustment, establishing the long lasting relationship between employee and employer and in achieving successful OS outcomes (Ashford and Black 1996; Buckley et al 1998; Cooper-Thomas et al 2004; Filstad 2004; Kammeyer-Mueller and Wanberg 2003; Kickul 2001). Small firms need to be conscious of the need to develop accurate expectations of newcomers that match the realities experienced when newcomers join the organisation. Small firms should utilise their advantage of size. The small numbers of employees in these firms, and 
the prevalence of informal processes, facilitates quicker and more extensive inclusion and assimilation of newcomers into their new work environments (Cardon and Stevens 2004).

\section{Limitations and Opportunities for further Research}

This exploratory study examined pre-encounter expectations and encounter experiences and resultant outcomes in small manufacturing firms from a socialisation agent perspective. Newcomer learning and adjustment is a process of interaction between both newcomers and organisational insiders (i.e. socialisation agents) and it is difficult to examine expectations and experiences of newcomer adjustment without exploring the nature of pre-encounter and encounter socialisation and resultant outcomes from both an individual and organisational insider perspective ("interactionist" perspective) (Griffin, Colella and Goparaju 2000; Jones 1983; Reichers 1987). The "interactionist" perspective has not received a great deal of empirical attention and there is a need for further research that adopts an "interactionist" approach towards OS.

Despite the findings of this study indicating that preemployment practices such as selection are important determinants of newcomer learning and adjustment, little has been done to examine the role of pre-employment practices such as recruitment and selection in socialising newcomers (Scholaris et al 2003). Further research is required to examine the effects of recruitment and selection practices on socialisation processes (Bauer, et al 1998). This is particularly so in the case of small firms.

\section{References}

Allen, D. G. (2006). Do organizational socialization tactics influence newcomer embeddedness and turnover? Journal of Management, 32, 237-256.

Ardts, J., Jansen, P. and Van der Velde, M. (2001). The breaking in of new employees: Effectiveness of socialization tactics and personnel instruments. Journal of Management Development, 20, 159167.

Ashford, S. J. and Black, J. S. (1996). Proactivity during organizational entry: The role of desire for control. Journal of Applied Psychology, 81, 199. 215.

Ashforth, B. E. and Saks, A. M. (1996). Socialization tactics: Longitudinal effects of newcomer adjustment. Academy of Management Journal, 39, 149-178.
As this study was limited to small manufacturing firms in the Hawke's Bay region of New Zealand, it would be inappropriate to extrapolate these findings to different types of small firms across New Zealand. Research suggests that contextual factors, such as geographic location, influence the nature of HRM practices in small firms in New Zealand (Gilbert and Jones 2000). Further studies of expectations and experiences of newcomer socialisation in small firms extended to different types of industries and locations would be useful to researchers, practitioners, policy makers and planners who have an interest in the small firm sector.

\section{Conclusions}

Most studies and literature dealing with newcomer socialisation relate to larger organisations. This study contributes to the socialisation literature by exploring the relationship between pre-encounter expectations and encounter experiences and resultant outcomes of newcomer socialisation in small manufacturing firms from the perspective of socialisation agents. The findings indicate that the degree of compatibility between preencounter expectations and encounter experiences during newcomer socialisation in small firms makes an important contribution to key outcomes such as performance and turnover. In addition, this exploratory study highlights further opportunities that exist to examine newcomer socialisation in the small firm context that should not be ignored. This is especially so when viewed against the background of the importance of small firms to national economies and employment creation, the difficulties small firms face in attracting and retaining skilled employees and the paucity of research in the area of newcomer socialisation in small firms.

Ashforth, B. E., Sluss, D. M. and Saks, A. M. (2007). Socialization tactics, proactive behavior, and newcomer learning: Integrating socialization models. Journal of Vocational Behavior, 70, 447 462.

Atkinson, C. (2007). Building high performance employment relationships in small firms. Employee Relations, 29, 506-519.

Babbie, E. (2004). The practice of social research (10th ed.). Belmont, CA: Wadsworth.

Bandura, A. (1977). Social learning theory. Englewood Cliffs, NJ: Prentice-Hall.

Barge, K. J. and Schlueter, D. W. (2004). Memorable messages and newcomer socialization. Western Journal of Communication, 68, 233-256.

Barrett, R. and Mayson, S. (2006). Exploring the intersection of HRM and entrepreneurship: Guest editors' introduction to the special edition on 
HRM and entrepreneurship. Human Resource Management Review, 16, 443-446.

Battisti, M. and Perry, M. (2008). Creating opportunity for small-firm exporters through regional free trade agreements: A strategic perspective from New Zealand. Australasian Journal of Regional Studies, 14, 275-285.

Bauer, T. N., Bodner, T., Erdogan, B., Truxillo, D. M. and Tucker, J. S. (2007). Newcomer adjustment during organizational socialization: A metaanalytic review of antecedents, outcomes, and methods. Journal of Applied Psychology, 92, 707721.

Beery, S. A. (2000). Approaches to socializing newcomers and new employee commitment. Unpublished master's thesis, Michigan State University.

Buckly, R. M., Fedor, J. G., Veres, J. G., Wiese, D. S. and Carraher, S. M. (1998). Investigating newcomer expectations and job-related outcomes. Journal of Applied Psychology, 83, 452-461.

Cable, D. M. and Parsons, C. K. (2001). Socialization tactics and person-organization fit. Personnel Psychology, 54, 1-23.

Cameron, A., Coetzer, A., Lewis, K., Massey, C. and Harris, C. (2006). HR management practices: Home-grown, but effective. Chartered Accountants Journal, 85, 33-34.

Cameron, A. F. and Massey, C. (1999). Small and medium sized enterprises: A New Zealand perspective. Auckland, New Zealand: Addison Wesley Longman.

Cardon, M. S. and Stevens, C. E. (2004). Managing human resources in small organizations: What do we know? Human Resource Management Review, 14, 295-323.

Carr, J. C., Pearson, A. W., Vest, M. J. and Boyer, S. L. (2006). Prior occupational experience, anticipatory socialization, and employee retention. Journal of Management, 32, 343-359.

Chao, G. T., O'Leary-Kelly, A. M., Wolf, S., Klein, H. J. and Gardner, P. D. (1994). Organizational socialization: Its content and consequences. Journal of Applied Psychology, 79, 730-743.

Chatman, J. A. (1991). Matching people and organizations: Selection and socialization in public accounting firms. Administrative Science Quarterly, 36, 459-484.

Coetzer, A. (2006). Managers as learning facilitators in small manufacturing firms. Journal of Small Business and Management Development, 13, 351362.
Coetzer, A. and Perry, M. (2008). Factors influencing employee learning in small businesses. Education and Training, 50, 648-660.

Cooper-Thomas, H. D. and Anderson, N. (2002). Newcomer adjustment: The relationship between organizational socialization tactics, information acquisition and attitudes. Journal of Occupational and Organizational Psychology, 75, 423-437.

Cooper-Thomas, H. D. and Anderson, N. (2006). Organisational socialization: A new theoretical model and recommendations for future research and HRM practices in organizations. Journal of Managerial Psychology, 21, 492-516.

Cooper-Thomas, H. D., Van Vianen, A. and Anderson, N. (2004). Changes in person-organization fit: The impact of socialization tactics on perceived and actual P-O fit. European Journal of Work and Organizational Psychology, 13, 52-78.

Department of Labour. (2009). Labour Market Reports. Wellington, New Zealand: Department of Labour.

Deshpande, S. and Golhar, D. (1994). HRM practices in large and small manufacturing firms: A comparative study. Journal of Small Business Management, 35, 49-56.

De Vos, A., Buyens. D. and Schalk, R. (2003). Psychological contract development during organizational socialization: Adaptation to reality and the role of reciprocity. Journal of Organizational Behavior, 24, 537-548.

Feldman, D. C. (1976). A practical program for employee socialization. Organizational Dynamics, 64-80.

Feldman, D. C. (1976). A contingency theory of socialization. Administrative Science Quarterly, 21, 433-452.

Feldman, D.C. (1981). The multiple socialization of organizational members. The Academy of Management Review, 6, 309-318.

Feldman, D. C. (1994). Who's socializing whom? The impact of socializing newcomers on insiders, work groups, and organizations. Human Resource Management Review, 4, 213-233.

Filstad, C. (2004). How newcomers use role models in organizational socialization. Journal of Workplace Learning, 16, 396-409.

Fisher, C. D. (1986). Organizational Socialization: An integrative review. Research in Personnel and Human Resources Management, 4, 101-145.

Flanagan, J.C. (1954). The critical incident technique, Psychological Bulletin, 51, 327-358. 
Garavan, T. N. and Morley, M. (1997). The socialization of high-potential graduates into the organization: Initial expectations, experiences and outcomes. Journal of Managerial Psychology, 12, 118-129.

Gilbert, J. and Jones, G. (2000). Managing human resources in New Zealand small business. Asia Pacific Journal of Human Resources, 38, 55-68.

Greenwell, T. C., Lee, J. and Naeger, D. (2007). Using the critical incident technique to understand critical aspects of the minor league spectator's experience. Sports Marketing Quarterly, 16, 190198.

Griffin, A. E. C., Colella, A. and Goparaju, S. (2000). Newcomer and organizational socialization tactics: An interactionist perspective. Human Resource Management Review, 10, 453-474.

Hart, Z. P., Miller, V. D. and Johnson, J. R. (2003). Socialization, resocialization, and communication relationships in the context of an organizational change. Communication Studies, 54, 483-495.

Heneman, R., Tansky, J. and Camp, S. (2000). HRM practices in small and medium-sized enterprises: Unanswered questions and future research perspectives. Entrepreneurship Theory and Practice, 25, 11-26.

Jones, G. R. (1983). Psychological orientation and the process of organizational socialization: An interactionist perspective. Academy of Management Review, 8, 464-474.

Jones, G. R. (1986). Socialization tactics, self-efficacy, and newcomers' adjustments to organizations. Academy of Management Journal, 29, 262-279.

Kammeyer-Mueller, J. D. and Wanberg, C.R. (2003). Unwrapping the organizational entry process: Disentangling multiple antecedents and their pathways to adjustment. Journal of Applied Psychology, 88. 779-794.

Kickul, J. (2001). Promises made, promises broken: An exploration of employee attraction and retention practices in small businesses. Journal of Small Business Management, 39, 320-335.

Kirchmeyer, C. (1995). Demographic similarity to the work group: A longitudinal study of managers at the early career stage. Journal of Organizational Behavior, 16, 67-83.

Kotey, B. and Sheridan, A. (2004). Changing HRM practices with firm growth. Journal of Small Business and Enterprise Development, 11, 474485.

Kotey, B. and Slade, P. (2005). Formal human resource management practices in small growing firms. Journal of Small Business Management, 43, 16-40.
Kristof, A. (1996). Person-organisation fit: An integrative review of its conceptualizations, measurements, and implications. Personnel Psychology, 49, 1-49.

Kristof-Brown, A. L., Zimmerman, R. D. and Johnson, E. C. (2005). Consequences of individuals' fit at work: A meta analysis of personjob, person-organization, person-group, and person-supervisor fit. Personnel Psychology, 58, 281-342.

Kwesiga, E. and Bell, P. (2004). Back to organizational socialization: Building a case for the advancement of women in organizations. Equal Opportunities International, 23, 3-20.

Lambrecht, J. J., Redmann, D. H. and Stitt-Gohdes, W. L. (2004). Learning the ropes: On-the-job experiences of computer users. Information Technology, Learning, and Performance Journal, 22, 13-32.

Lewis, K., Massey, C., Ashby, M., Coetzer., A. and Harris, C. (2007) Business assistance for SMEs: New Zealand owner-managers make their assessment. Journal of Small Business and Enterprise Development, 14, 551-566.

Louis, M. R. (1980). Surprise and sense-making: What newcomers experience in entering unfamiliar organizational settings. Administrative Science Quarterly, 25, 226-251.

Louis, M. R., Posner, B. Z. and Powell, G. N. (1983). The availability and helpfulness of socialization practices. Personnel Psychology, 36, 857-866.

Massey, C. (2005). Entrepreneurship and small business management in New Zealand. Auckland, New Zealand: Pearson Education.

McAdam, R. (2000). The implementation of reengineering in SMEs: A grounded study. International Small Business Journal, 18, 29-45.

McAdam, R. (2002). Large scale innovationreengineering methodology in SMEs: Positivism and phenomenological approaches. International Small Business Journal, 20, 33-52.

Miles, B. M. and Huberman, A. M. (1994). Qualitative data analysis (2nd ed.). California, USA: Sage Publications.

Ministry of Economic Development. (2008). SMEs in New Zealand: Structure and Dynamics. Wellington, New Zealand: Ministry of Economic Development.

Mitchell, T. R., Holtom, B. C., Lee, T. W., Sablynski, C. J. and Erez, M. (2001). Why people stay: Using job embeddedness to predict voluntary turnover. The Academy of Management Journal, 44, 1102-1121. 
Morrison, E. W. (1993). Longitudinal study of the effects of information seeking on newcomer socialization. Journal of Applied Psychology, 78, 173-183.

Morrison, E. W. (2002). Newcomers' relationships: The role of social network ties during socialization. Academy of Management Journal, 45, 1149-1160.

Nicholson, N. and Arnold, J. (1991). From expectations to experiences: Graduates entering a large corporation. Journal of Organizational Behavior, 12, 413-429.

Ostroff, C. and Kozlowski, S.W. (1992). Organizational socialization as a learning process: The role of information acquisition. Personnel Psychology, 45, 849-874.

Patton, M. Q. (2002). Qualitative Evaluation and Research Methods (3rd ed.). Sage, California USA.

Porter, L. W. and Steers, R. M. (1993). Organizational, work, and personal factors in employee turnover and absenteeism. Psychological Bulletin, 80, 151176.

Raub, S., Alvarez, L. and Khanna. (2006). The different roles of corporate and unit level human resources managers in the hospitality industry. International Journal of Contemporary Hospitality Management, 18, 135-144.

Reichers, A. E. (1987). An interactionist perspective on newcomer socialization rates. The Academy of Management Review, 12, 278-287.

Robertson, I. T., and Smith, M. (2001). Personnel selection. Journal of Occupational and Organizational Psychology, 74, 441-472.

Saks, A. M. (1994). A psychological process investigation for the effects of recruitment source and organization information on job survival. Journal of Organizational Behavior, 15, 225-244.

Saks, A. M. and Ashforth, B. E. (1997). Organizational socialization: Making sense of the past and present as a prologue for the future. Journal of Vocational Behavior, 51, 234-279.

Saks, A. M. and Ashforth, B. E. (2000). The role of dispositions, entry strssors, and behavioural plasticity theory in predicting newcomers' adjustment to work. Journal of Organizational Behavior, 21, 43-62.

Saks, A. M., Uggerslev, K. L. and Fassina, N. E. (2006). Socialization tactics and newcomer adjustment: A meta-analytic review and test of a model. Journal of Vocational Behavior, 70, 413446.
Schein, E. H. (1968). Organizational socialization and the profession of management. Industrial Management Review, 9, 1-16.

Schluter, J., Seaton, P. and Chaboyer, W. (2007). Critical incident technique: A user's guide for nurse researchers. Journal of Advanced Nursing, 61, 107-114.

Scholaris, D., Lockyer, C. and Johnson, H. (2003). Anticipatory socialisation: The effect of recruitment and selection experiences on career expectations. Career Development International, 8, 182-197.

Silverman, D. (2000). Doing qualitative research: $A$ practical handbook. Sage, Thousand Oaks: CA.

Slattery, J. P., Selvarajan, T. T. and Anderson, J. E. (2002). Influences of new employee development practices on temporary employee work-related attitudes. Human Resource Development Quarterly, 10, 279-303.

Starr, J. A. and Fondas, N. (1992). A model of entrepreneurial socialization and organization formation. Entrepreneurship Theory and Practice, 1, 67-76.

Statistics New Zealand. (2007). New Zealand business demography statistics. Wellington, New Zealand.

Stevens, G. R. (2007). Job-matching and employee diversity: an exploratory study. Journal of Small Business and Enterprise Development, 14, 719731.

Stitt-Gohdes, W. L., Lambrecht, J. J. and Redmann, D. H. (2000). The critical incident technique in job behavior research. Journal of Vocational Education Research, 25, 1-15.

Sutton, G. and Griffin, M. A. (2004). Integrating expectations, experiences, and psychological contract violations: A longitudinal study of new professionals. Journal of Occupational and Organizational Psychology, 77, 493-514.

Van Maanen, J. (1978). People Processing: Strategies of organizational socialization. Organizational Dynamics, 19-36.

Van Maanen, J. and Schein, E. H. (1979). Toward a theory of organizational socialization. Research in Organizational Behavior, 1, 209-264.

Vaz, M. T. D. N., Cesario, M. and Fernandes, S. (2006). Interaction between innovation in small firms and their environments: An exploratory study. European Planning Studies, 14, 95-109.

Wanberg, C. R. and Kammeyer-Mueller, J. D. (2000). Predictors and outcomes of proactivity in the socialization process. Journal of Applied Psychology, 85, 373-385. 
Wanous, J. P. (1992). Organizational Entry: Recruitment, Selection, Orientation, and Socialization. Addison-Wesley, Reading, MA.

Wanous, J. P., Poland, T. D., Premack, S. L. and Davis, K. S. (1992). The effects of met expectations on newcomer attitudes and behaviors: A review and meta-analysis. Journal of Applied Psychology, 77, 288-297.
Wiesner, R. and McDoanld, J. (2001). Bleak house or bright prospect? Human resource management in Australian SMEs. Asia Pacific Journal of Human Resources, 39, 31-53. 